\title{
Emerging antiplatelet agents, differential pharmacology, and clinical utility
}

This article was published in the following Dove Press journal:

Journal of Blood Medicine

29 May 2010

Number of times this article has been viewed

\section{Pranab Das' \\ Carrie S Oliphant ${ }^{2}$ \\ Elizabeth Beach ${ }^{3}$ \\ Rashmi Thapa ${ }^{4}$}

'Assistant Professor, Division of Cardiology, Department of Internal Medicine, University of Tennessee Health Sciences Center, Memphis, Tennessee, USA; ${ }^{2}$ Cardiology Clinical Pharmacy Specialist, Department of Pharmacy, Methodist University Hospital, and Assistant Professor University of Tennessee College of Pharmacy, Memphis, Tennessee, USA; ${ }^{3}$ PGY-I Pharmacy Practice Resident, Department of Pharmacy, Methodist University Hospital, Memphis, Tennessee, USA; ${ }^{4}$ Resident, Department of Internal Medicine, University of Tennessee Health Sciences Center, Memphis, Tennessee, USA
Correspondence: Pranab Das Division of Cardiology, Department of Internal Medicine, University of Tennessee Health Sciences Center, Memphis, Tennessee, USA Tel + I 90| 4485750

Fax + I 90। 448 I I 23

Email pdas@uthsc.edu
Abstract: The aspirin-clopidogrel combination is the current gold standard antiplatelet regimen following percutaneous coronary intervention and for the treatment of acute coronary syndrome. Despite the clinical benefit of this combination, patients continue to have vascular events. Another purinergic ( $\left.\mathrm{P} 2 \mathrm{Y}_{12}\right)$ receptor antagonist, prasugrel, became available last year. Although prasugrel is superior to clopidogrel in reducing clinical endpoints, a higher bleeding rate has been identified particularly in high-risk patients. Ticagrelor, a reversible $\mathrm{P} 2 \mathrm{Y}_{12}$ receptor antagonist currently being evaluated for approval, is also more potent than clopidogrel but has a similar bleeding risk. Two additional $\mathrm{P} 2 \mathrm{Y}_{12}$ antagonists are being investigated that will be available as an intravenous formulation. Apart from the $\mathrm{P} 2 \mathrm{Y}_{12}$ receptor antagonists, multiple other agents are being developed with unique mechanisms of platelet inhibition. These agents are being studied as an alternative to or in combination with clopidogrel. The antiplatelet agents currently under development include: thrombin receptor antagonists, phosphodiesterase inhibitors, a thromboxane-prostaglandin receptor antagonist, a serotonin receptor blocker, a platelet adhesion antagonist, nitric oxide-releasing aspirin, a glycoprotein VI antagonist, and a cyclooxygenase inhibitor. The purpose of this review is to describe the efficacy and safety profiles of the emerging antiplatelet agents and their role in the treatment of atherosclerotic cardiovascular diseases.

Keywords: antiplatelet agents, safety, efficacy, clinical pharmacology, clinical trials

\section{Introduction}

Platelets have an important role in primary hemostasis and endothelial repair. In addition, by activation of their numerous surface receptors and release of several inflammatory mediators, platelets promote atherothrombosis. ${ }^{1}$ Coronary artery disease (CAD), stroke, and peripheral vascular disease are known as "atherothrombotic" manifestations of atherosclerosis. Inhibition of platelet aggregation and secretion is paramount to reducing adverse outcomes in these clinical conditions associated with heightened platelet reactivity.

Aspirin, a cyclooxygenase (COX) inhibitor, has been used for centuries due to its anti-inflammatory, antipyretic, and analgesic properties. More recently, aspirin has been used as an antiplatelet agent to prevent thromboembolic vascular events. The thienopyridines are another class of antiplatelet agents that inhibit adenosine diphosphate-induced platelet aggregation via the $\mathrm{P} 2 \mathrm{Y}_{12}$ receptor located on the platelet surface. Adenosine diphosphate (ADP) is a very potent platelet agonist, whose signals to cause platelet aggregation are mediated via two purinergic platelet receptors, $\mathrm{G}_{\mathrm{q}}$ coupled $\mathrm{P} 2 \mathrm{Y}_{12}$ receptor and $\mathrm{G}_{\mathrm{i}}$ coupled $\mathrm{P} 2 \mathrm{Y}_{12}$ receptor. ${ }^{2}$ Due to selective tissue distribution of 
$\mathrm{P} 2 \mathrm{Y}_{12}$ receptors, the thienopyridines, referred to as $\mathrm{P} 2 \mathrm{Y}_{12}$ receptor antagonists, are potent antiplatelet agents that are extensively used in clinical and interventional cardiology.

Ticlopidine, the first $\mathrm{P} 2 \mathrm{Y}_{12}$ antagonist, is approved for use with aspirin as dual antiplatelet therapy following coronary artery stenting. ${ }^{3}$ However, due to serious side effects of ticlopidine, it is no longer the drug of choice having been replaced by clopidogrel, a second generation thienopyridine $\mathrm{P} 2 \mathrm{Y}_{12}$ antagonist with a more favorable side effect profile. Several large, randomized clinical trials have demonstrated the benefit of aspirin-clopidogrel combination in reducing death, myocardial infarction (MI), and target vessel revascularization among patients with acute coronary syndrome (ACS) including unstable angina, non-ST-segment elevation MI (NSTEMI) and ST-segment elevation MI (STEMI) with or without percutaneous coronary intervention (PCI). ${ }^{4-9}$ The combination of aspirin and clopidogrel has now become the favored combination in the realm of interventional cardiology following PCI, and also in the medical management of patients with ACS.

Clopidogrel has properties that make it less than an ideal antiplatelet agent. It has a slow onset of action of at least two hours following a $600 \mathrm{mg}$ oral loading dose, and between 6-15 hours after a $300 \mathrm{mg}$ loading dose to achieve adequate platelet inhibition. This delayed onset of action can be problematic when quicker platelet inhibition is desired as in ACS. In addition, the irreversible blockade of platelet activity can delay coronary artery bypass graft (CABG) surgery for 5-7 days in an effort to reduce the rate of CABG-related bleeding and the need for re-operation and transfusion.

Although aspirin and clopidogrel are widely used in the management of ACS and after PCI, some patients continue to have thromboembolic events. One possible explanation is the concept of antiplatelet resistance the has been reported with both aspirin and clopidogrel. ${ }^{10,11}$ The proposed mechanisms for antiplatelet resistance include, alternative signaling pathways for platelet activation, high stress conditions, genetic polymorphisms and drug interactions. ${ }^{10,12}$ Variability in response to clopidogrel therapy has been recently demonstrated on platelet function assays. This phenomenon of "clopidogrel hyporesponsiveness" has been linked to increased thrombotic events which could be potentially fatal. ${ }^{13,14}$ Tailoring of clopidogrel therapy based on platelet reactivity as assessed by in vitro platelet assays was met with initial enthusiasm, but this approach has been found to be far from ideal. ${ }^{15,16}$ Genetic polymorphisms with reduced function variant alleles of the CYP2C19 hepatic cytochrome $\mathrm{P} 450$ isoenzyme involved in the metabolism of clopidogrel to its active metabolite has been associated with platelet hypo-responsiveness. ${ }^{17}$

As a result of these problems associated with clopidogrel, newer agents are being developed with the hope of overcoming these shortcomings. Ideally, any agent aimed at replacing clopidogrel would have a faster onset of action and more uniform platelet inhibition without a significant increase in bleeding risk. In addition to finding a replacement for clopidogrel, some antiplatelet agents are being investigated as add-on therapy to the combination of aspirin and clopidogrel. Table 1 outlines the various classes of antiplatelet agents that are currently available or under investigation. We aim to discuss the role of emerging antiplatelet agents in atherosclerotic cardiovascular diseases.

\section{Newer P2Y ${ }_{12}$ antagonists}

While ticlopidine and clopidogrel have been used extensively ever since their inception, newer agents hold a great deal of promise due to their differential pharmacology. ${ }^{18}$ Table 2 describes the various types of $\mathrm{P}_{2} \mathrm{Y}_{12}$ antagonists that are currently in use, or in the later stages of development.

Table I Classes of antiplatelet agents

\begin{tabular}{|c|c|}
\hline Class & Drugs \\
\hline \multirow[t]{2}{*}{ Cyclooxygenase inhibitors } & Aspirin \\
\hline & Indobufen \\
\hline ADP receptor antagonists & Ticlopidine \\
\hline \multirow[t]{2}{*}{ (Thienopyridines) } & Clopidogrel \\
\hline & Prasugrel \\
\hline ADP receptor antagonists & Cangrelor \\
\hline \multirow[t]{2}{*}{ (Nonthienopyridines) } & Ticagrelor \\
\hline & Elinogrel \\
\hline \multirow[t]{4}{*}{ Glycoprotein Ilb/llla inhibitors } & Abciximab \\
\hline & Tirofiban \\
\hline & Eptifibatide \\
\hline & Defibrotide \\
\hline \multirow[t]{4}{*}{ Phosphodiesterase inhibitors } & Dipyridamole \\
\hline & Cilostazol \\
\hline & NT-702 (parogrelil \\
\hline & hydrochloride, NM-702) \\
\hline Protease-activated receptor (PAR-I) & SCH 530348 \\
\hline inhibitors (thrombin receptor inhibitor) & E5555 \\
\hline Thromboxane $A_{2}$ receptor inhibitor & Terutroban (SI8886) \\
\hline \multirow[t]{4}{*}{ Platelet adhesion antagonist } & ARCI779 \\
\hline & CIqTNF-related \\
\hline & protein-I \\
\hline & DZ-697b \\
\hline Nitric oxide releasing aspirin & NCX-4016 \\
\hline \multirow[t]{5}{*}{ Collagen-platelet interaction inhibitor } & PR-15 \\
\hline & Monoclonal antibodies \\
\hline & Aptamers \\
\hline & Small molecule peptide \\
\hline & inhibitors \\
\hline
\end{tabular}

Abbreviation: ADP, adenosine diphosphate. 
Table $2 \mathrm{P} \mathrm{Y}_{12}$ antagonists

\begin{tabular}{|c|c|c|c|c|c|c|}
\hline Agent & Morphology & $\begin{array}{l}\text { Mode of } \\
\text { P2Y }_{12} \\
\text { inhibition }\end{array}$ & $\begin{array}{l}\text { Reversibility } \\
\text { of } \mathrm{P}_{2 Y_{12}} \\
\text { blockade }\end{array}$ & $\begin{array}{l}\text { Mode of } \\
\text { administration }\end{array}$ & $\begin{array}{l}\text { Dosing } \\
\text { frequency }\end{array}$ & $\begin{array}{l}\text { Approval } \\
\text { status }\end{array}$ \\
\hline Ticlopidine & Thienopyridine & Indirect & Irreversible & Oral & Twice daily & Approved \\
\hline Clopidogrel & Thienopyridine & Indirect & Irreversible & Oral & Once daily & Approved \\
\hline Prasugrel & Thienopyridine & Indirect & Irreversible & Oral & Once daily & Approved \\
\hline Ticagrelor & $\begin{array}{l}\text { Cyclo-pentyl- } \\
\text { triazolo-pyrimidine }\end{array}$ & Direct & Reversible & Oral & Twice daily & Under review \\
\hline Cangrelor & ATP analog & Direct & Reversible & Intravenous & $\begin{array}{l}\text { During } \\
\text { procedure }\end{array}$ & $\begin{array}{l}\text { Phase III } \\
\text { clinical trials }\end{array}$ \\
\hline Elinogrel & - & Direct & Reversible & $\begin{array}{l}\text { Oral and } \\
\text { intravenous }\end{array}$ & Once daily & $\begin{array}{l}\text { Phase II } \\
\text { clinical trials }\end{array}$ \\
\hline
\end{tabular}

Abbreviations: ATP, adenosine triphosphate; $\mathrm{P}_{2} \mathrm{Y}_{12}$, Purinergic.

\section{Prasugrel}

Prasugrel is a new thienopyridine adenosine diphosphate (ADP) receptor antagonist. Like clopidogrel and ticlopidine, prasugrel is a selective and irreversible inhibitor of the platelet P2 $\mathrm{Y}_{12}$ receptor. ${ }^{19}$ It is a pro-drug that is converted to its active metabolite R-138727 by cytochrome (CYP) P450 enzymes. The CYP3A4 and CYP2B6 enzymes are primarily responsible for metabolic conversion with CYP2C9 and CYP2C19 being secondary pathways. For prasugrel, conversion to the active metabolite requires only one CYP450 dependent oxidation step, while clopidogrel requires two enzymatic steps. As a result, prasugrel has a faster onset of action with a peak plasma concentration of the active metabolite 30 minutes post dosing. ${ }^{20}$ The half life of the active metabolite of prasugrel is 7.4 hours (ranging from 2 hours to 15 hours) while the half life of the active metabolite for clopidogrel is 8 hours. Due to the differing enzymes involved in metabolic conversion of prasugrel to its active form, the drug interaction reported between clopidogrel and proton pump inhibitors does not seem to be clinically significant. ${ }^{21}$ Unlike with clopidogrel, common functional CYP genetic variants do not affect active drug metabolite levels, inhibition of platelet aggregation, or clinical cardiovascular event rates in persons treated with prasugrel. ${ }^{22}$

Early Phase I and II clinical trials demonstrated prasugrel has a faster onset of action and more complete platelet inhibition compared to clopidogrel. The Joint Utilization of Medications to Block Platelets Optimally (JUMBO-TIMI 26) trial was the first Phase II study to evaluate the use of prasugrel in patients undergoing elective or urgent $\mathrm{PCI} .{ }^{23} \mathrm{In}$ this study, 904 patients were randomized to prasugrel low dose (40 mg loading dose, $7.5 \mathrm{mg}$ daily dose), intermediate dose (60 mg loading dose, $10 \mathrm{mg}$ daily dose), or high dose (60 mg loading dose, $15 \mathrm{mg}$ daily) or standard clopidogrel (300 mg loading dose, $75 \mathrm{mg}$ daily dose) for approximately 30 days. All patients received aspirin $325 \mathrm{mg}$ daily. The primary endpoint of the study was non-CABG related significant hemorrhage, which was defined by the composite of TIMI major and minor bleeding criteria. Efficacy was measured by the incidence of major adverse coronary events. Variation was not significant in the primary endpoint between the combined prasugrel groups and clopidogrel, $1.7 \%$ and $1.2 \%$, respectively (Hazard Ratio (HR) $=1.42(95 \%$ confidence interval (CI) $0.40-5.08), P=0.59$ ). Major adverse coronary events occurred at a similar rate in the combined prasugrel arm $(7.2 \%)$ and clopidogrel arm (9.4\%) (HR $=0.76(95 \%$ CI 0.46-1.24), $P=0.26$ ). The authors concluded that the use of prasugrel resulted in similar bleeding and clinical events compared to clopidogrel.

The Prasugrel in Comparison to Clopidogrel for Inhibition of Platelet Activation and Aggregation (PRINCIPLE) Thrombolysis in Myocardial Infarction (TIMI) 44 Trial was a randomized, double-blind, double-dummy, Phase II crossover trial enrolling 201 subjects. ${ }^{24}$ Patients undergoing planned PCI were randomized to treatment with prasugrel or clopidogrel with administration of a loading dose within one hour of PCI. The treatment regimens were prasugrel $60 \mathrm{mg}$ loading dose and $10 \mathrm{mg}$ daily dose or clopidogrel $600 \mathrm{mg}$ loading dose and $150 \mathrm{mg}$ daily dose for 14 days. After completion of this phase of the study, patients were switched to the alternative medication for an additional 14 days. The primary end point of the loading dose phase was the degree of inhibition of platelet aggregation (IPA) at 6 hours. Prasugrel had a significantly higher degree of IPA $(74.8 \pm 13 \%)$ compared to clopidogrel $(31.8 \pm 21.1 \%)$ $(P<0.0001)$. For the maintenance phase of the study, the primary endpoint was degree of IPA at day 14. Results for this phase also demonstrated superiority of prasugrel versus clopidogrel, $61.3 \pm 17.8 \%$ and $46.1 \pm 21.3 \%$, respectively $(P<0.0001)$. No TIMI major bleeding events were observed in either treatment arm during the study period. Thus, both 
the loading and maintenance doses of prasugrel had a greater degree of platelet inhibition than high dose clopidogrel.

The positive results of the PRINCIPLE-TIMI 44 trial led to a Phase III clinical trial, Trial to Asses Improvement in Therapeutic Outcomes by Optimizing Platelet Inhibition with Prasugrel (TRITON-TIMI 38). ${ }^{25}$ TRITON-TIMI 38 was a 13,608 patient, randomized, double-blinded, multinational Phase III clinical trial designed to assess the efficacy and safety of prasugrel versus clopidogrel. Patients with moderate to high risk ACS, including NSTEMI and STEMI, with scheduled PCI, were randomized to receive either prasugrel $60 \mathrm{mg}$ loading dose followed by $10 \mathrm{mg}$ daily or clopidogrel $300 \mathrm{mg}$ loading dose followed by $75 \mathrm{mg}$ daily for 6 to 15 months. The primary end point was the combined occurrence rate of cardiovascular death, nonfatal myocardial infarction, or nonfatal stroke. Non-CABG TIMI major bleeding, non-CABG TIMI life-threatening bleeding and TIMI major and minor bleeding were the main safety endpoints evaluated. The primary endpoint occurred in $9.9 \%$ of patients receiving prasugrel and $12.1 \%$ of patients receiving clopidogrel $(\mathrm{HR}=0.81$ (95\% CI 0.73-0.90), $P<0.001)$. This benefit of prasugrel over clopidogrel was seen as early as day 3, which is likely attributed to the rapid onset of action of prasugrel. This reduction in the primary endpoint was principally driven by a significant reduction in the rate of nonfatal myocardial infarction in the prasugrel arm (7.3\% vs 9.5\%; HR = 0.76 (95\% CI 0.67-0.85), $P<0.001)$. Other statistically significant endpoints favoring prasugrel included urgent target-vessel revascularization $(2.5 \%$ vs $3.7 \%$ ) and stent thrombosis ( $1.1 \%$ vs $2.4 \%)$. The overall reduction in stent thrombosis was remarkable regardless of the type of stent used. There were a significantly greater number of non-CABG TIMI major bleeding events with prasugrel than with clopidogrel, $2.4 \%$ and $1.8 \%$, respectively $(\mathrm{HR}=1.32$ (95\% CI 1.03-1.68), $P=0.03)$. Additionally, there was a greater rate of non-CABG TIMI life-threatening bleeding in the prasugrel group ( $1.4 \%$ vs $0.9 \%$; HR $=1.52$ (95\% CI 1.08-2.13), $P=0.01)$, which included fatal $(0.4 \%$ vs $0.1 \%, \mathrm{HR}=4.19(95 \% \mathrm{CI} 1.58-11.11), P=0.002)$ and nonfatal bleeding $(1.1 \%$ vs $0.9 \%, \mathrm{HR}=1.25(95 \% \mathrm{CI}$ 0.87-1.81), $P=0.23)$. CABG-related TIMI major bleeding was also higher in the prasugrel treated patients $(13.4 \%$ vs $3.2 \%, \mathrm{HR}=4.73$ (95\% CI 1.90-11.82), $P<0.001)$. Three subgroups, namely individuals with a history of previous stroke or transient ischemic attack (TIA), patients 75 years or older, and patients weighing $60 \mathrm{~kg}$ or less did not show favorable clinical benefits from prasugrel due to the increased risk of bleeding. In patients with a history of cerebrovascular disease, prasugrel was associated with an increase in intracranial hemorrhage. Use of prasugrel in patients with ACS thus results in a decreased rate of clinical events with an increase in bleeding events. In the STEMI subgroup study from TRITON TIMI 38, patients with STEMI undergoing PCI, prasugrel was found to be more effective than clopidogrel for prevention of ischemic events, without an apparent excess in bleeding. ${ }^{26}$

Prasugrel is now indicated to reduce the rate of thrombotic cardiovascular events (including stent thrombosis) in patients with ACS with planned PCI. The US package insert contains a black box warning related to the increased risk of bleeding in special populations. The warning recommends against the use of prasugrel in patients with active bleeding, prior TIA or stroke and the need for CABG surgery. Patients 75 years or greater should not receive prasugrel unless the benefit outweighs the risk. For patients weighing $60 \mathrm{~kg}$ or less, the package labeling suggests considering prasugrel $5 \mathrm{mg}$ daily even though this dosage was not studied in the TRITON-TIMI 38 trial. The American Heart Association and the American College of Cardiology have issued updates to the guidelines for the treatment of STEMI and PCI, which incorporated the latest clinical trial results for prasugrel. ${ }^{27} \mathrm{~A}$ loading dose of prasugrel $60 \mathrm{mg}$ is now recommended for primary PCI in STEMI patients as an alternative to clopidogrel. For STEMI patients undergoing nonprimary PCI, prasugrel $60 \mathrm{mg}$ may be given within one hour after PCI in patients who did not receive fibrinolytic therapy and once the coronary anatomy is known to avoid using in patients who require CABG. After stenting, prasugrel $10 \mathrm{mg}$ daily may be given as an alternative to clopidogrel $75 \mathrm{mg}$ daily for at least 12 months regardless of stent type and can continue beyond 15 months after DES placement. In reference to patients undergoing a planned CABG, prasugrel should be held for at least 7 days prior to the procedure.

\section{Ticagrelor}

Ticagrelor is a reversible oral $\mathrm{P} 2 \mathrm{Y}_{12}$ receptor antagonist, the first in a new class known as the cyclopentyltriazolopyrimidines. Since ticagrelor does not require metabolic conversion for activity, it has a rapid onset of action within 2-4 hours of administration. An active metabolite has been identified for ticagrelor, which is believed to contribute to the antiplatelet activity of the parent compound. Peak plasma concentrations are achieved in 1.5 to 3 hours with steady state being reached after 2 to 3 days. As a result of its reversible inhibition at the $\mathrm{P} 2 \mathrm{Y}_{12}$ receptor, the mean elimination half-life is 6 to 12 hours regardless of dose. 
The pharmacodynamics, pharmacokinetics and safety profile of ticagrelor has been studied against clopidogrel in the Pharmacodynamics, pharmacokinetics and safety of the oral reversible $\mathrm{P} 2 \mathrm{Y}_{12}$ receptor antagonist AZD6140 with aspirin in patients with atherosclerosis trial (DISPERSE and DISPERSE-2 Phase II trials). ${ }^{28,29}$ The DISPERSE trial was a dose ranging study comparing ticagrelor to clopidogrel in patients with stable atherosclerotic disease. ${ }^{28} \mathrm{~A}$ total of 200 patients were randomized to receive ticagrelor $(50,100$, or $200 \mathrm{mg}$ twice a day or $400 \mathrm{mg}$ daily) or clopidogrel $75 \mathrm{mg}$ daily for a total of 28 days. Aspirin was given to all patients at a dose of 75-100 mg daily. The primary pharmacodynamic endpoint was the inhibition of ADP-induced platelet aggregation at various time points. The degree of platelet inhibition with the three highest doses of ticagrelor $(100 \mathrm{mg}$ and $200 \mathrm{mg}$ twice daily and $400 \mathrm{mg}$ daily) was greater (approximately 90\%-95\%) and more rapid than the lowest dose of ticagrelor and clopidogrel (approximately 60\%). The extent of platelet inhibition did not differ among the three highest doses of ticagrelor. Bleeding was the most common adverse event and occurred more frequently with the higher doses of ticagrelor. Dyspnea was a unique side effect found in the ticagrelor patients, the incidence of which increased with increasing doses, and none of these events were considered serious. Ticagrelor $100 \mathrm{mg}$ bid and $200 \mathrm{mg}$ bid were well tolerated compared to $400 \mathrm{mg}$ daily with a greater degree of platelet inhibition than clopidogrel and lower dose ticagrelor. In the DISPERSE-2 trial, a total of 990 patients with NSTEMI were randomized to receive ticagrelor or clopidogrel for up to 3 months. ${ }^{29}$ The ticagrelor dose was either $90 \mathrm{mg}$ or $180 \mathrm{mg}$ twice daily. Patients in the clopidogrel group received a loading dose of $300 \mathrm{mg}$ followed by $75 \mathrm{mg}$ daily. All patients received aspirin, initially $325 \mathrm{mg}$ followed by 75-100 mg daily. The primary safety endpoint of major or minor bleeding at 4 weeks did not differ among the groups, $9.8 \%$ in the $90 \mathrm{mg}$ group ( $P=0.43$ vs clopidogrel), $8.0 \%$ in the $180 \mathrm{mg}$ group ( $P=0.96$ vs clopidogrel) and $8.1 \%$ in the clopidogrel arm. The rate of bleeding in patients undergoing CABG less than 5 days after drug administration was lower in the ticagrelor arms. Numerically, the rate of myocardial infarctions was lower in the ticagrelor arms, but the rate of cardiovascular death was similar between the groups. This study lacked adequate power to assess clinical events. As was seen in the first DISPERSE study, the rate of dyspnea was higher in the ticagrelor arms, with $48 \%$ of the patients having persistent symptoms during the study. Ventricular pauses lasting greater than 2.5 seconds was also seen more frequently in the ticagrelor arms. The number of patients with at least one pause and more than three episodes was significantly higher in the $180 \mathrm{mg}$ group than clopidogrel. The authors concluded that ticagrelor demonstrated similar safety and tolerability to clopidogrel.

The Phase II ONSET/OFFSET trial evaluated the timing of the antiplatelet effect of ticagrelor versus clopidogrel in patients with stable coronary disease. ${ }^{30} \mathrm{~A}$ total of 123 patients were randomized to receive ticagrelor $180 \mathrm{mg}$ loading dose followed by $90 \mathrm{mg}$ twice daily or clopidogrel $600 \mathrm{mg}$ loading dose followed by $75 \mathrm{mg}$ daily for 6 weeks. Aspirin $75-100 \mathrm{mg}$ daily was given to all patients. At all time points, $0.5,1,2,4,8$ and 24 hours after loading and at 6 weeks, ticagrelor had a significantly greater inhibition of platelet aggregation (IPA) $(P<0.0001$, all comparisons). In addition, two hours after the loading dose was administered a greater percentage of patients in the ticagrelor arm had achieved $>50 \%$ IPA ( $98 \%$ vs $31 \%, P<0.0001)$ and $>70 \%$ IPA $(90 \%$ vs $16 \%, P<0.0001)$. The offset of ticagrelor was also faster as evidenced by a comparable IPA result for ticagrelor at day 3 to that of clopidogrel at day 5. This study demonstrates that ticagrelor has faster onset and offset action compared to clopidogrel due its reversible nature.

The largest and latest Phase III trial of ticagrelor (platelet inhibition and patient outcomes (PLATO)) compared ticagrelor and clopidogrel in patients with or without STEMI. ${ }^{31} \mathrm{~A}$ total of 18,624 patients were randomized to ticagrelor $180 \mathrm{mg}$ loading dose followed by $90 \mathrm{mg}$ twice daily or clopidogrel $300 \mathrm{mg}$ loading dose followed by $75 \mathrm{mg}$ daily. In patients who had PCI, an additional dose of assigned study drug was given, either ticagrelor $90 \mathrm{mg}$ or clopidogrel $300 \mathrm{mg}$. Aspirin $75-100 \mathrm{mg}$ daily was given to all patients, unless post stent, in which case $325 \mathrm{mg}$ daily was permitted for six months. The primary efficacy endpoint was a composite of death from vascular causes, myocardial infarction or stroke. Safety was measured as the first occurrence of a major bleeding event using the study specific criteria. The rate of vascular events at 12 months occurred at a lower rate in the ticagrelor group (9.8\%) compared to the clopidogrel group $(11.7 \%)(\mathrm{HR}=0.84$ (95\% CI 0.77-0.92), $P<0.001)$. This endpoint was driven by statistical reductions in the rate of MI and vascular death in the ticagrelor arm. Death from any cause, predefined as a secondary endpoint, occurred in $4.5 \%$ of ticagrelor patients versus $5.9 \%$ of clopidogrel patients (HR $=0.78$ (95\% CI 0.69-0.89), $P<0.001)$. The rate of stent thrombosis in patients who received a stent during the study was lower with ticagrelor $(1.3 \%)$ over clopidogrel $(1.9 \%)(\mathrm{HR}=0.67(95 \% \mathrm{CI} 0.50-0.91), P=0.009)$. The rate of major bleeding events as defined by the PLATO investi- 
gators, did not differ significantly between ticagrelor and clopidogrel, $11.6 \%$ and $11.2 \%$, respectively $(\mathrm{HR}=1.04(95 \%$ CI 0.95-1.13), $P=0.43$ ). When the TIMI criteria for major bleeding were analyzed, the lack of difference between the treatment arms persisted (7.9\% vs 7.7\%; HR $=1.03(95 \%$ CI 0.93-1.15), $P=0.57)$. The rate of CABG-related bleeding using both the study definition and TIMI criteria was similar in both arms (both, $P=0.32$ ). Non-CABG related major bleeding was significantly higher with ticagrelor using the study criteria $(4.5 \%$ vs $3.8 \%, \mathrm{HR}=1.19(95 \% \mathrm{CI}$ $1.02-1.38)$ ) and TIMI criteria (2.8\% vs $2.2 \%, \mathrm{HR}=1.25$ (95\% CI 1.03-1.53)) ( $P=0.03$, both endpoints). Other adverse events seen in the PLATO trial were similar to those seen in previous studies. Dyspnea was more commonly seen with ticagrelor, $13.8 \%$ versus $7.8 \%(P<0.001)$, although only $0.9 \%$ of the ticagrelor patients discontinued therapy as a result of this side effect. During the first week of therapy there was a significantly higher incidence of ventricular pauses greater than or equal to 3 seconds in the ticagrelor $\operatorname{arm}(5.8 \%$ vs $3.6 \%, P=0.01)$. In this study, uric acid and serum creatinine values were increased in the ticagrelor arm for the duration of treatment but similar to clopidogrel one month after discontinuing therapy. The authors concluded that ticagrelor significantly reduced the incidence of vascular events without a significant increase in the rate of major bleeding.

\section{Cangrelor}

Cangrelor is also a reversible, nonthienopyridine $\mathrm{P} 2 \mathrm{Y}_{12}$ receptor antagonist. Unlike, the other $\mathrm{P} 2 \mathrm{Y}_{12}$ inhibitors, cangrelor is being developed as an intravenous (IV) formulation. Cangrelor does not require metabolic conversion, which results in its ultra-short half-life of approximately 2.6 to 3.3 minutes. This short half-life allows the effects of cangrelor to be offset within 20-50 minutes following cessation of the infusion. Given the drug's unique properties, studies have been conducted in the setting of ACS and PCI. Cangrelor was studied in a Phase II trial compared to placebo in patients with unstable angina and non-Q wave MI. ${ }^{32}$ In this study, cangrelor was well tolerated and bleeding rates were similar to placebo. The use of cangrelor in patients undergoing urgent or elective PCI was studied in a 2-part Phase II trial enrolling a total of 399 patients. ${ }^{33}$ Results from the first part of the study showed cangrelor to have a similar rate of bleeding compared to placebo. The second part of the study was a head to head comparison with abciximab. Bleeding rates were comparable between cangrelor and abciximab. Platelet inhibition with cangrelor was seen within 15 minutes of starting the infusion and platelet function returned to baseline within 15 minutes of stopping the infusion. Platelet inhibition in the abciximab arm was seen 24 hours after the infusion was terminated, as expected.

STEP-AMI (Safety, Tolerability and Effect on Patency in Acute Myocardial Infarction) examined the use of cangrelor alone or in combination with low dose alteplase (tPA) to standard dose tPA. ${ }^{34}$ This study was stopped early due to a shift in drug development by the manufacturer. Preliminary results indicated improved coronary artery patency in the patients who received cangrelor and tPA over cangrelor alone but no benefit compared to tPA alone.

Two larger scale, Phase III randomized trials of cangrelor versus standard therapy to achieve optimal management of platelet inhibition (CHAMPION) were recently published. ${ }^{35,36}$ These studies (CHAMPION PLATFORM and CHAMPION PCI) enrolling over 14,000 patients were terminated early by the manufacturer when interim efficacy analysis indicated no benefit of cangrelor over placebo. The study designs were similar with the exception of clopidogrel timing. In CHAMPION PCI, clopidogrel was given before PCI, whereas in CHAMPION PLATFORM, clopidogrel was given after PCI. The primary efficacy endpoint was a composite of death, MI or ischemia driven revascularization, which did not differ between cangrelor and placebo. An interesting finding was the rate of stent thrombosis, which was significantly reduced by cangrelor in the CHAMPION PLATFORM study but not the CHAMPION PCI study. The manufacturer of cangrelor has changed the focus of their research to investigate the role of cangrelor as bridge therapy when an antiplatelet therapy is needed short term, when oral drugs cannot be used, or when a short drug half-life is needed (for example, in bridging patients on drugs like clopidogrel who need to undergo surgery). The ongoing maintenance of platelet inhibition with cangrelor after discontinuation of thienopyridines in patients undergoing surgery (BRIDGE) study is investigating this strategy and will enroll approximately 200 patients. ${ }^{37}$

\section{Elinogrel (PRT 060I28)}

PRT 060128 or elinogrel is the only direct acting, reversible P2 $\mathrm{Y}_{12}$ antagonist with a unique structure that is being studied both as an IV and oral form. Thus it has the potential of being administered IV in the hospital, and then switched over to the oral form for continuation of therapy. Elinogrel is directly active without the need for any transformation. Most of the drug is excreted unchanged in the urine and feces. About $10 \%-20 \%$ of the drug is metabolized by demethylation (PRT 060301), and is the only prominent circulating metabolite in 
plasma. In an initial pharmacokinetic and pharmodynamic study, single IV doses of elinogrel between 1 and $40 \mathrm{mg}$ were administered over 20 minutes to 5 groups of 8 healthy subjects ( 6 active, 2 placebo) in a randomized, double-blinded fashion. ${ }^{38}$ Platelet aggregation with $10 \mu \mathrm{M}$ ADP at 6 minutes was measured. All IV doses were well tolerated with no serious or clinically significant adverse events. The increase in plasma drug concentration of elinogrel is dose related, and the degree of platelet inhibition is also proportional to plasma drug concentration. The maximum tolerated dose using a pre-defined bleeding time criteria was reached with the $40 \mathrm{mg}$ dose. Average terminal half-life of the $40 \mathrm{mg}$ dose of elinogrel was about 11 hours.

In an animal model (mouse model), the efficacy of PRT 060128 (PRT 128) and clopidogrel were compared by Andre et al. ${ }^{39}$ Mice were administered PRT $128(7.5,20,60 \mathrm{mg} / \mathrm{kg})$ 2 hours prior to experiments or clopidogrel $50 \mathrm{mg} / \mathrm{kg}$ for 3 days with 5-10 animals per group. Bleeding times and thrombosis were measured. PRT 128 demonstrated dose-proportional antithrombotic activity in vivo at plasma concentrations which had minimal effect on tail bleeding times. At the highest concentrations of PRT 128, its antithrombotic activity was superior to clopidogrel. This finding of superior efficacy of PRT 128 was further evaluated in human subjects by Gurbel et al. ${ }^{40} \mathrm{~A}$ total of 45 subjects with established coronary artery disease with previous coronary stent placement on chronic aspirin and clopidogrel therapy were screened for high platelet reactivity (HPR) defined as $>43 \%$ platelet aggregation to $5 \mu \mathrm{M}$ ADP. A total of 20 out of these 45 patients had HPR. Following administration of single oral dose of $60 \mathrm{mg}$ PRT 128, platelet function was assessed at baseline, 4 hours, 6 hours, and 24 hours post-dosing with several pharmacodynamic assays. Platelet reactivity fell within 4 hours of dosing, the earliest time point evaluated, and was reversible within 24 hours. Elinogrel thus reversibly overcomes high platelet reactivity seen as a result of nonresponsiveness to dual antiplatelet therapy with clopidogrel and aspirin. A simultaneous assessment of CYP2C19*2 showed a more frequent association with HPR (77\% versus $16 \%, P=0.0004$ ).

The safety and feasibility of IV elinogrel before primary PCI for STEMI as an adjunctive antiplatelet therapy was studied in a Phase II trial (the Early Rapid Reversal of Platelet thrombosis with IV elinogrel before PCI to optimize reperfusion in acute myocardial infarction (ERASE MI). ${ }^{41}$ This was a pilot, randomized, placebo-controlled, dose-escalation study designed to study tolerability of single, IV elinogrel in escalating doses (10 mg, $20 \mathrm{mg}, 40 \mathrm{mg}$, and $60 \mathrm{mg}$ ). All patients received aspirin, unfractionated heparin, and $600 \mathrm{mg}$ clopidogrel given after diagnostic angiogram but before PCI, and another $300 \mathrm{mg} 4$ hours after PCI. Other antithrombotic agents were not allowed while the use of glycoprotein IIb/IIIa inhibitors was strongly recommended. A total of 70 patients in four cohorts were enrolled. The primary outcome was inhospital bleeding per the TIMI and GUSTO bleeding scales. The incidence of bleeding events was low, and similar with all doses of elinogrel versus placebo. There were no differences in serious adverse events with elinogrel compared to placebo.

A Phase II safety and efficacy study of elinogrel is currently ongoing (INNOVATE-PCI) ${ }^{42}$ This is a multicenter, randomized, double-blind, triple-dummy, clopidogrelcontrolled study of IV and oral PRT 060128 compared to clopidogrel in patients undergoing nonurgent (including elective) PCI. After diagnostic angiography, patients scheduled for nonurgent PCI will be randomized to clopidogrel or to one of three dose levels of elinogrel.

\section{Thrombin receptor antagonists}

Thrombin is the main mediator of blood coagulation, first in the initial platelet activation, and then in the amplification and cleavage of fibrinogen to fibrin. Thrombin is also the most potent platelet activator, activating platelets at an extremely low concentration (lower that those required for activation of the coagulation cascade). Thrombin is not influenced by $\mathrm{P} 2 \mathrm{Y}_{12}$ receptor antagonists or aspirin. Selective blocking of the thrombin receptor effectively inhibits thrombin dependent platelet activation (the pathway involved in thrombosis). However, selective thrombin receptor blockade spares the collagen dependent activation of the pathway involved in hemostasis. This blockade does not affect the generation of fibrin by thrombin and thrombin's effects on coagulation factors are spared. Proteinase activated receptor-1 (PAR-1) is a high-affinity receptor for thrombin, and the key platelet thrombin receptor. Thrombin acts on PAR-1 by cleaving the N-terminal domain, and then exposing a tethered ligand that binds and activates the receptor. Thus, thrombin receptor antagonists by selectively inhibiting PAR-1 portend to cause a favorable balance of antithrombotic efficacy with less risk of bleeding. Inhibition of thrombin-mediated PAR-1 activation could add a new dimension in the domain of antiplatelet therapy. In addition, PAR-1 is also expressed in endothelial cells, cardiomyocytes, and smooth muscle cells. It acts as a modulator in acute inflammation and vascular repair. Thus, PAR-1 blockade may also be of interest in healing following PCI to reduce in-stent re-stenosis. ${ }^{43}$ 
SCH 530348 (also known as vorapaxar), an orally active, low-molecular weight, nonpeptide, competitive PAR-1 antagonist (tricyclic 3-phenylpyridine antagonist) potently inhibits thrombin-induced platelet aggregation without affecting measures of coagulation or increasing bleeding time. Both the association and dissociation rates of $\mathrm{SCH}$ 530348 with PAR-1 are slow, yet the inhibition is reversible and dose-dependent. A SCH 530348 loading dose of $20 \mathrm{mg}$ achieves $>80 \%$ inhibition of thrombin receptor activating peptide (TRAP)-induced platelet aggregation at 2 hours in approximately $50 \%$ of patients. With a $40 \mathrm{mg}$ loading dose, nearly $70 \%$ patients had $>80 \%$ inhibition after 1 hour and $96 \%$ by 2 hours. Both the 1 and $2.5 \mathrm{mg}$ maintenance doses sustained $>80 \%$ inhibition at 30 and 60 days in all patients tested. Recovery of platelet function to $50 \%$ of baseline after a single dose occurs slowly in a dose dependent manner (1,2, and 3 weeks after 10, 20, and $40 \mathrm{mg}$ doses respectively). In patients receiving a maintenance dose of $2.5 \mathrm{mg}$ daily for 28 days, recovery of platelet function was observed 2 to 3 weeks after the last dose. SCH 530348 is rapidly absorbed, and has excellent bioavailability upon oral administration with a pharmacodynamic half life of greater than 7 days. It is metabolized and eliminated primarily by biliary and gastrointestinal routes. Renal clearance is less than $5 \%$, thus clearance is no different among healthy and renally impaired patients. Exposure to SCH 530348 is dose dependent with an inter-individual variability of $20 \%-40 \%$ that does not depend on sex, ethnicity or fasting state. It is slowly, but extensively metabolized mostly via oxidation by the CYP3A4 system. Co-administration with ketoconazole and rifampin increases and decreases its exposure respectively. ${ }^{44,45}$

In the Phase II thrombin receptor antagonist - percutaneous coronary intervention (TRA-PCI) trial, the safety and efficacy of SCH 530348 among 1,031 patients undergoing nonurgent PCI or coronary angiography with intention to perform PCI were evaluated during a 60 -day period. ${ }^{46}$ In addition to aspirin and clopidogrel, and heparin or bivalirudin, patients were randomized to receive one of the three loading doses of $\mathrm{SCH}$ 530348 (10 mg, $20 \mathrm{mg}$, or $40 \mathrm{mg}$ ) or placebo at least 1 hour before PCI. Patients that underwent PCI $(n=573)$ were randomized to receive one of the three oral daily maintenance doses of SCH 530348 (0.5 mg, $1 \mathrm{mg}$, or $2.5 \mathrm{mg}$ ) or placebo for 60 days. The primary end point was the composite of TIMI major or minor bleeding in the PCI cohort. Overall, SCH 530348 did not cause an increase in the occurrence of the primary safety end point compared to placebo $(3.3 \%$ with placebo versus $2.8 \%$ combined SCH 530348 groups).
The rates of bleeding by maintenance dose were also similar. Among patients undergoing CABG, CABG-related bleeding was similar between SCH 530348 and placebo. The secondary end point of death, major cardiovascular events or stroke was also similar between SCH 530348 and placebo.

Another Phase II clinical trial of 117 Japanese NSTEMI patients receiving aspirin, ticlopidine and heparin, found that the addition of SCH 530348 (20 mg or $40 \mathrm{mg}$ loading followed by $1 \mathrm{mg}$ or $2.5 \mathrm{mg}$ maintenance dose) for 60 days did not cause an increase in the primary end point of TIMI major and minor bleeding compared to placebo. ${ }^{47}$ Evidence from these two trials show that SCH 530348 when added to current standard of care therapy, does not cause increased bleeding, and may even offer a potential benefit of lowering thrombotic events.

Two Phase III trails are currently ongoing with SCH 530348. The Thrombin Receptor Antagonist for Secondary Prevention (TRA-2 degrees P-TIMI 50) trial is a double-blind, randomized, placebo controlled trial that will evaluate the efficacy of SCH 530348 plus standardof-care therapies in secondary prevention with prior MI, stroke or peripheral vascular disease. ${ }^{45}$ Planned enrollment will be 20,000 patients, randomized to receive $\mathrm{SCH}$ $5303482.5 \mathrm{mg}$ or placebo for a minimum of 1 year. The primary end point is the composite of cardiovascular death, MI, urgent coronary revascularization or stroke. The Thrombin Receptor Antagonist Clinical Event reduction in acute coronary syndrome (TRACER) is a double-blinded, placebo-controlled trial of $>10,000$ patients with NSTEMI that will compare $40 \mathrm{mg}$ loading dose of SCH 530348 and $2.5 \mathrm{mg}$ maintenance dose versus matching placebo in addition to aspirin and clopidogrel for at least 1 year. ${ }^{48}$ The primary end point is the composite of cardiovascular death, MI, stroke, re-hospitalization for ACS, and urgent target revascularization during a minimum 1-year follow up. The estimated completion date is July 2011.

Another PAR-1 receptor inhibitor E5555 is currently being tested in Phase II safety studies. E5555 is a potent PAR-1 antagonist that targets the G-coupled receptor modulating thrombin-platelet-endothelial interactions. This drug was studied in a Phase II trial among healthy volunteers and patients with CAD treated with aspirin with or without clopidogrel. ${ }^{49}$ Platelet activity was assessed after pre-incubation with escalating concentrations of E5555 $(20 \mathrm{ng} / \mathrm{ml}, 50$ $\mathrm{ng} / \mathrm{ml}$, and $100 \mathrm{ng} / \mathrm{ml}$ ) in healthy volunteers, CAD patients treated with aspirin, and CAD patients treated with aspirin and clopidogrel combination ( $\mathrm{n}=10$, for each group). E5555 inhibited a number of platelet biomarkers. Platelet 
inhibition was usually moderate, and was not seemingly dose-dependent without TRAP stimulation. E5555 caused 10\%-15\% inhibition of ADP- and collagen-induced platelet aggregation in plasma, but not in whole blood. TRAP-induced aggregation was inhibited almost completely. E5555 potentiates the antiplatelet effects of aspirin alone, and also the combination of aspirin and clopidogrel. E5555 thus promises to be a potential addition to current antiplatelet therapy.

\section{Phosphodiesterase inhibitors}

Cilostazol is a phosphodiesterase (PDE) III inhibitor that is currently indicated as a first line agent among patients with intermittent claudication due to its beneficial effect on increasing claudication distance. ${ }^{50}$ In addition to its antiplatelet effects, it also possesses antiproliferative properties by reducing smooth muscle proliferation and intimal hyperplasia following endothelial injury. Recent studies have shown benefits of cilostazol as triple therapy in addition to aspirin and clopidogrel in reducing major cardiac adverse events in patients with acute coronary syndrome and following PCI. ${ }^{51,52}$

NT-702 (parogrelil hydrochloride), a selective phosphodiesterase (PDE)-3 inhibitor has vasodilatory as well as anti-inflammatory properties. In in-vitro studies, NT-702 potently and concentration-dependently inhibited human platelet aggregation induced by ADP, collagen, and thrombin. It is being studied for the treatment of claudication. ${ }^{53}$

\section{Thromboxane-prostaglandin receptor (TP) antagonist}

TP receptor antagonists block the effects of thromboxane on platelets, monocytes, and vascular endothelium while allowing endothelial prostacyclin production via the COX-1 pathway. In addition, they also inhibit other thromboxane receptor ligands such as endoperoxidase, prostanoids, and isoprostanes. These agents thus cause vasodilation, and inhibit platelet aggregation.

Terutroban (formerly S18886) is an oral, reversible TP receptor antagonist with antithrombotic, antivasoconstrictive, and antiatherosclerotic properties. ${ }^{54}$ Terutroban provides fast and potent antithrombotic effects comparable to that provided by aspirin-clopidogrel combination with a more favorable bleeding risk profile. In a pharmacokinetic-pharmodynamic study, the maximal inhibitory effect was achieved in 1 hour after dosing in patients with peripheral arterial disease. ${ }^{55}$ A large, Phase III trial (PERFORM) is currently comparing the efficacy and safety of terutroban versus aspirin in second- ary prevention of cardiovascular and cerebrovascular events in patients with recent history of stroke or TIA..$^{56,57}$

\section{Serotonin receptor blocker}

Serotonin causes platelet aggregation and vasoconstriction. Sarpogrelate, a selective 5-hydroxytryptamine 2A (5-HT2A) receptor antagonist has been developed as an antiplatelet agent and has been used in Japan, China and Korea for many years in patients with peripheral vascular disease (PVD). In a Phase II study with this drug in Europe for intermittent claudication, this drug was well tolerated, and had shown a trend towards improving claudication distance. ${ }^{58}$ This drug is shown to be noninferior and safer than aspirin in stroke patients. ${ }^{59}$

\section{Platelet adhesion antagonist}

von Willebrand factor (vWF) is vital to platelet adhesion and aggregation. ARC-1779 is an optimized, second-generation, PEGylated aptamer that exerts a novel antithrombotic action through targeting the A1 domain of activated vWF and inhibiting the binding of platelet receptor glycoprotein Ib. It thus reduces platelet adhesion, and aggregation and thereby thrombus formation in arterial beds. ARC-1779 has potential therapeutic benefit in acute coronary syndromes and von Willebrand's disease, as well as in vWF-related platelet disorders such as thrombotic thrombocytopenic purpura (TTP) and other thrombotic microangiopathies. As an aptamer, the actions of ARC-1779, unlike other antiplatelet agents, can be readily reversed by binding to a complementary sequence of oligonucleotides; this ability offers potential therapeutic benefit in surgery.

In Phase I and II clinical trials, ARC-1779 has exhibited favorable pharmacokinetic, pharmacodynamic and safety properties in healthy individuals and patients with TTP. The first-in-human evaluation of ARC1779 has shown a doseand concentration-dependent inhibition of vWF activity and platelet function with a duration of effect suitable for the intended clinical use in acute coronary syndromes. ${ }^{60}$ Even in the setting of acute myocardial infarction, where vWF is increased, ARC1779 potently and specifically inhibits vWF activity and vWF dependent platelet function. ${ }^{61}$ The study entitled, ARC1779 in Patients with acute myocardial infarction undergoing PCI (vITAL-1), has been terminated. ${ }^{62}$

\section{Nitric oxide-releasing aspirin}

The addition of a nitric oxide-releasing moiety to aspirin would offer added benefit beyond the antiplatelet effects of aspirin since nitric oxide has a combination of antithrombotic, antiatherogenic and vasodilatory effects. NCX-4016 is a 
prototype of this family of molecules. NCX-4016 undergoes first pass metabolism in the liver, and is metabolized to salicylic acid and NCX-4015. NCX 4016 has been effective in the inhibition of COX activity and also monocyte activation with tissue factor expression. In a rat model of carotid balloon injury treatment, NCX-4016 resulted in increased availability of nitric oxide and a lower rate of restenosis, when compared with that of aspirin. This effect was associated with diminished vascular smooth muscle cell proliferation. This agent also has a better gastroenteric safety profile as compared to aspirin alone. In a prospective, randomized, single-blind, parallel-group trial among 44 patients with intermittent claudication comparing 4 weeks of therapy with NCX 4016 (800 mg BID) versus aspirin $100 \mathrm{mg}$ daily, exercise induced endothelial dysfunction was prevented by NCX 4016, but not by aspirin. ${ }^{63}$

\section{Glycoprotein VI antagonist}

After vessel wall disruption, platelets are adhered to subendothelial collagen through the glycoprotein VI (GPVI) receptors, and subsequently are activated. PR-15 is a soluble variant of GPVI receptor. It is a monoclonal antibody to GPVI receptor. It binds to exposed collagen and prevents GPVI mediated firm platelet adhesion and activation. Unlike other antiplatelet drugs, PR-15 targets receptors that are found on the activated platelets, which may potentially reduce the risk of bleeding associated with antiplatelet agents. In vitro studies have evaluated the ability of PR-15 to inhibit human platelet aggregation. The degree of reduction of aggregation produced was similar to the highest concentration regardless of collagen addition. PR-15 did not increase bleeding time in vitro. It has shown to be safe in animal models. A Phase I study of 30 healthy volunteers has been completed and the pharmacokinetics and pharmacodynamics (platelet aggregation) of six ascending single IV doses of PR-15 have been assessed. ${ }^{64}$ This study has been terminated by the company and no further details are available.

\section{Cyclooxygenase inhibitors}

Indobufen, a potent but reversible platelet COX-1 inhibitor has been shown to be effective as an antithrombotic agent. It was shown to be effective in prevention of graft occlusion after $\mathrm{CABG}$ and for the prevention of thromboembolic events in coronary artery disease. ${ }^{65}$ Studies comparing indobufen to warfarin for prevention of stroke have not been very compelling for indobufen as it caused slightly higher stroke events. ${ }^{66}$

Table 3 details the nonpurine antagonists as they are being developed for clinical use. Table 4 enlists the pharmacological properties of promising antiplaletet agents.

\section{Discussion}

Among the newer antiplatelet agents discussed in this review, prasugrel has already been approved for clinical use, while ticagrelor is expected to be available in the near future. Since prasugrel produces a more thorough inhibition of platelet aggregation with a faster onset of action without much variability in response, it should be the drug of choice in an ideal patient following percutaneous coronary intervention. However, prasugrel's use is somewhat limited by the fact that it causes more bleeding particularly among patients over 75 years of age, and patients weighing less than $60 \mathrm{~kg}$. Prasugrel is contraindicated in patients with a prior history of stroke or TIA. Ticagrelor offers a distinct advantage over currently available P2 $\mathrm{Y}_{12}$ receptor antagonists, in that it is a reversible agent with a fast onset of action while not causing an increased risk of bleeding. The unique side effects of dyspnea, ventricular pauses and laboratory changes do not appear to be clinically significant, but warrant closer and long-term monitoring. While cangrelor is unique due to its IV formulation and short half-life, making it attractive for use during PCI, two Phase III trials showed no significant advantage of this drug over conventional therapy. Its role as a bridging

Table 3 Newer antiplatelet compounds in clinical trials

\begin{tabular}{llll}
\hline Agent & Target & Phase of development & Indications \\
\hline SCH530348 & Thrombin receptor PAR-I & Phase III & $\begin{array}{l}\text { Acute coronary syndrome } \\
\text { Cardiovascular disease }\end{array}$ \\
E5555 & Thrombin receptor, PAR-I & Phase II & Acute coronary syndrome \\
$\begin{array}{l}\text { Terutroban (SI8886) } \\
\text { Cilostazol }\end{array}$ & $\begin{array}{l}\text { Thromboxane receptor } \\
\text { Phosphodiesterase III }\end{array}$ & $\begin{array}{l}\text { Phase III } \\
\text { Phase IV }\end{array}$ & Stroke: secondary prevention \\
Sarpogrelate & & Approved for PVD \\
& 5-HT2A serotonin inhibitor & Phase IV & Trials for PCl, stroke, DM \\
& & & Approved for PVD in Japan \\
\end{tabular}

Abbreviations: DM, diabetes mellitus; PAR-I, protease-activated recepter-I; PCl, percutaneous coronary intervention; PVD, peripheral vascular disease; 5-HT2A, 5-hydroxytryptamine $2 \mathrm{~A}$. 
Table 4 Differential pharmacology of emerging antiplatelet agents

\begin{tabular}{lllllll}
\hline & Prasugrel & Cangrelor & Ticagrelor & Elinogrel & SCH 530348 & Terutroban \\
\hline Route of administration & PO & IV & PO & IV/PO & PO & PO \\
Loading dose & $60 \mathrm{mg}$ & $4 \mathrm{mcg} / \mathrm{kg} / \mathrm{min}$ & $180 \mathrm{mg}$ & $80 \mathrm{mg}$ IV & $40 \mathrm{mg}$ & $10-30 \mathrm{mg}$ \\
Maintenance dose & $5-10 \mathrm{mg}$ & $4 \mathrm{mcg} / \mathrm{kg} / \mathrm{min}$ & $90 \mathrm{mg}$ & $50-150 \mathrm{mg} \mathrm{BID}$ & $2.5 \mathrm{mg}$ & $10-30 \mathrm{mg}$ \\
& & & & (being defined) & & $1 \mathrm{~h}$ \\
Time to platelet inhibition & $2 \mathrm{hrs}$ & $30 \mathrm{~min}$ & $2 \mathrm{hrs}$ & $4 \mathrm{hrs}$ & $1 \mathrm{~h}$ \\
Half life & $3.7 \mathrm{hrs}$ & $3-5 \mathrm{~min}$ & $12 \mathrm{hrs}$ & $1 \mathrm{hrs}$ & $126-269 \mathrm{hrs}$ & $6-10 \mathrm{hrs}$ \\
\hline
\end{tabular}

Abbreviations: BID, twice a day; IV, intravenous; PO, per oral.

therapy prior to surgery is being defined. Elinogrel on the other hand will be available in both an oral and IV form. If supported by the ongoing Phase II and III trials, elinogrel holds a great promise in interventional cardiology as this can be used as an IV form during PCI, transitioning to an oral form for maintenance therapy. The most ideal, and probably the most promising of all the emerging antiplatelet agents are the thrombin receptor antagonists. As these new agents have an excellent safety profile with less bleeding, a positive efficacy outcome from the ongoing trials will herald a new era in the field of antiplatelet therapy. The other agents discussed in this review await further clinical data to define their role in present atherosclerotic disease management.

\section{Disclosures}

The authors report no conflict of interest in this work

\section{References}

1. Davi G, Patrono C. Platelet activation and atherothrombosis. $N$ Engl J Med. 2007;357:2482-2494.

2. Cattaneo M. New P2Y ${ }_{12}$ inhibitors. Circulation. 2010;121:171-179.

3. Schomig A, Neumann FJ, Kastrati A, et al. A randomized comparison of antiplatelet and anticoagulant therapy after the placement of coronary-artery stents. N Engl J Med. 1996;334: 1084-1089.

4. Yusuf S, Zhao F, Mehuta SR, et al. Effects of clopidogrel in addition to aspirin in patients with acute coronary syndromes without ST-segment elevation. N Engl J Med. 2001;345:494-502.

5. Mehta SR, Yusuf S, Peters RJG, et al. Effects of pretreatment with clopidogrel and aspirin followed by long-term therapy in patients undergoing percutaneous coronary intervention: the PCI CURE study. Lancet. 2001;358:527-533.

6. Steinhubl SR, Beger PB, Mann JT, et al. for the CREDO investigators. Early and sustained dual antiplatelet therapy following percutaneous coronary intervention: a randomized controlled trial. JAMA. 2002; 288:2411-2420

7. Sabatine MS, Cannon CP, Gibson CM, et al; for the CLARITY-TIMI 28 investigators. Addition of clopidogrel to aspirin and fibrinolytic therapy for myocardial infarction with ST-segment elevation. $N$ Engl J Med. 2005;352:1179-1189.

8. Sabatine MS, Cannon CP, Gibson CM, et al. Effect of clopidogrel pretreatment before percutaneous coronary intervention in patients with ST-elevation myocardial infarction treated with fibrinolytics: the PCI-CLARITY study. JAMA. 2005;294: 1224-1232.

9. Chen ZM, Jiang LX, Chen YP, et al. Addition of clopidogrel to aspirin in 45,852 patients with acute myocardial infarction: randomised placebo-controlled trial. Lancet. 2005;366:1607-1621.
10. Gasparyan AY, Watson T, Lip GY. The role of aspirin in cardiovascular prevention: implications of aspirin resistance. J Am Coll Cardiol. 2008; 51:1829-1843.

11. Bonvini RF, Reny JL, Mach F, et al. Acute coronary syndrome and its antithrombotic treatment: focus on aspirin and clopidogrel resistance. Curr Vasc Pharmacol. 2009; 7:198-208.

12. Sharma RK, Reddy HK, Singh VN, et al. Aspirin and clopidogrel hyporesponsiveness and nonresponsiveness in patients with coronary artery stenting. Vasc Health Risk Manag. 2009;5:965-972.

13. Serebruany VL, Steinhubl SR, Berger PB, et al. Variability in platelet responsiveness to clopidogrel among 544 individuals. J Am Coll Cardiol. 2005;45:246-251.

14. Snoep JD, Hovens HM, Eikenboom JC, et al. Nonresponsiveness in patients undergoing percutaneous coronary intervention with stenting: a systematic review and meta-analysis. Am Heart J. 2007; 154:221-231.

15. Bonello L, Camoin-Jau L, Arques S, et al. Adjusted clopidogrel loading doses according to vasodilator-stimulated phosphoprotein phosphorylation index decrease rate of major adverse cardiovascular events in patients with clopidogrel resistance: a multicenter randomized prospective study. J Am Coll Cardiol. 2008;51:1404-1411.

16. Bonello L, Camoin-Jau L, Armero S, et al. Tailored clopidogrel loading dose according to platelet reactivity monitoring to prevent acute and subacute stent thrombosis. Am J Cardiol. 2009;103:5-10.

17. Mega JL, Close SL, Wiviott SD, et al. Cytochrome P-450 polymorphism and response to clopidogrel. N Engl J Med. 2009;360:354-362.

18. Oliphant CS, Doby JB, Blade CL, et al. Emerging P2 $\mathrm{Y}_{12}$ receptor antagonists: role in coronary artery disease. Curr Vasc Pharmacol. 2010;8:93-101.

19. Jakubowski J, Payne C, Brandt J, et al. The platelet inhibitory effects and pharmacokinetics of prasugrel after administration of loading and maintenance doses in healthy subjects. J Cardiovasc Pharmacol. 2006;47:377-384.

20. Brandt J, Payne C, Wiviott S, et al. A comparison of prasugrel and clopidogrel loading doses on platelet function: magnitude of platelet inhibition is related to active metabolite formation. Am Heart $J$. 2007;153(1):66.e9-66.e16.

21. Small DS, Farid NA, Payne CD, et al. Effects of the proton pump inhibitor lansoprazole on the pharmacokinetics and pharmacodynamics of prasugrel and clopidogrel. J Clin Pharmacol. 2008;48:475-484.

22. Mega JL, Close SL, Wiviott D, et al. Cytochrome P450 genetic polymorphisms and the response to prasugrel: relationship to pharmacokinetic, pharmacodynamic, and clinical outcomes. Circulation. 2009;119:2553-2560.

23. Wiviott S, Antman E, Winters K, et al. Randomized comparison of prasugrel, a novel thienopyridine $\mathrm{P}_{2} \mathrm{Y}_{12}$ receptor antagonist, with clopidogrel in percutaneous coronary intervention. Circulation. 2005;111:3366-3373.

24. Wiviott SD, Trenk D, Frelinger AL, et al. Prasugrel compared with high loading- and maintenance-dose clopidogrel in patients with planned percutaneous coronary intervention: the Prasugrel in Comparison to Clopidogrel for Inhibition of Platelet Activation and Aggregation Thrombolysis in Myocardial Infarction 44 trial. Circulation. 2007;116:2923-2932. 
25. Wiviott SD, Braunwald E, McCabe CH, et al. Prasugrel versus clopidogrel in patients with acute coronary syndromes. $N$ Engl $J$ Med. 2007;357:2001-2015.

26. Montalescot G, Wiviott SD, Braunwald E, et al. TRITON-TIMI 38 investigators. Prasugrel compared with clopidogrel in patients undergoing percutaneous coronary intervention for ST-elevation myocardial infarction (TRITON-TIMI 38): double-blind, randomized controlled trial. Lancet. 2009;373:723-731.

27. Kushner FG, Hand M, Smith SC Jr, et al. 2009 Focused updates: ACC/AHA guidelines for the management of patients with STelevation myocardial infarction (Updating the 2004 Guideline and 2007 Focused Update) and ACC/AHA/SCAI guidelines on percutaneous coronary intervention (Updating the 2005 Guideline and 2007 Focused Update). J Am Coll Cardiol. 2009;54: $2205-2241$.

28. Husted S, Emanuelsson H, Heptinstall S, et al. Pharmacodynamics, pharmacokinetics, and safety of the oral reversible P2 $\mathrm{Y}_{12}$ antagonist AZD6140 with aspirin in patients with atherosclerosis: a double-blind comparison to clopidogrel with aspirin. Eur Heart J. 2006;27:1038-1047.

29. Cannon CP, Husted S, Harrington RA, et al. Safety, tolerability, and initial efficacy of AZD6140, the first reversible oral adenosine diphosphate receptor antagonist, compared with clopidogrel, in patients with non-ST segment elevation acute coronary syndrome: primary results of the DISPERSE-2 trial. J Am Coll Cardiol. 2007;50:1844-1854.

30. Gurbel PA, Bliden KP, Butler K, et al. Randomized doubleblind assessment of the ONSET and OFFSET of the antiplatelet effects of ticagrelor versus clopidogrel in patients with stable coronary artery disease: the ONSET/OFFSET study. Circulation. 2009;120:2577-2585

31. Wallentin L, Becker RC, Budaj A, et al. for the PLATO Investigators. Ticagrelor versus clopidogrel in patients with acute coronary syndrome. N Engl J Med. 2009;361:1045-1057.

32. Storey RF, Oldroyd KG, Wilcox RG. Open multicenter study of the P2Y receptor antagonist AR-C69931MX assessing safety, tolerability and activity in patients with acute coronary syndromes. Thromb Haemost. 2001;85:401-407.

33. Greenbaum AB, Grines CL, Bittl JA, et al. Initial experience with an intravenous $\mathrm{P} 2 \mathrm{Y}_{12}$ receptor antagonist in patients undergoing percutaneous coronary intervention: results from a 2-part, phase II, multicenter, randomized, placebo- and active-controlled trial. Am Heart J. 2006;151:689.e1-689.e10.

34. Greenbaum AB, Ohman M, Gibson CM, et al. Preliminary experience with intravenous $\mathrm{P} 2 \mathrm{Y}_{12}$ platelet receptor inhibition as an adjunct to reduced-dose alteplase during acute myocardial infarction: results of the safety, tolerability and effect on patency in acute myocardial infarction (STEP-AMI) angiographic trial. Am Heart $J$. 2007;154:702-709.

35. Harrington RA, Stone GW, McNulty S, et al. Platelet inhibition with cangrelor in patients undergoing PCI. $N$ Engl J Med. 2009;361: 2318-2329

36. Bhatt DL, Lincoff AM, Gibson CM, et al. Intravenous platelet blockade with cangrelor during PCI. N Engl J Med. 2009;361:2330-2341.

37. Clinical Trials.gov. Protocol NCT00767507. Maintenance of platelet inhibition with cangrelor (BRIDGE). http://www.clinicaltrials.gov/ ct2/show/NCT00767507?term=cangrelor\&rank=5 Accessed Feb 2, 2010.

38. Lieu HD, Conley PB, Andre P, et al. Initial intravenous experience with PRT 060128, an orally available, direct acting, and reversible $\mathrm{P}_{2} \mathrm{Y}_{12}$ inhibitor. J Thromb Haemost. 2007;5(2):P-T-292.

39. Andre P, Jurek M, Sim D, et al. PRT 060128, a novel, direct-acting orally available $\mathrm{P} 2 \mathrm{Y}_{12}$ antagonist, confers superior antithrombotic activity over clopidogrel in a mouse thrombosis model. J Thromb Haemost. 2007;5(2):O-W-031.
40. Gurbel PA, Bliden KP, Antonio MJ, et al. The effect of elinogrel on high platelet reactivity during dual antiplatelet therapy and the relation to CYP 2C19*2 genotype: first experience in patients. J Thromb Haemost. 2010;8:43-53.

41. Berger JS, Roe MT, Gibson M, et al. Safety and feasibility of adjunctive antiplatelet therapy with intravenous elinogrel, a direct acting and reversible $\mathrm{P} 2 \mathrm{Y}_{12}$ ADP-receptor antagonist, before primary percutaneous intervention in patients with ST-elevation myocardial infarction: The Early Rapid Reversal of Platelet thrombosis with intravenous elinogrel before PCI to optimize reperfusion in acute myocardial infarction (ERASE MI) pilot trial. Am Heart $J$. 2009;158:998-1004

42. Clinical Trials.gov. Protocol NCT00751231. A phase 2 safety and efficacy study of PRT060128, a novel intravenous and oral P2Y inhibitor, in non-urgent PCI. http://www.clinicaltrials.gov/ct2/show/NCT007512 31?term=NCT00751231\&rank = 1 Accessed Dec 16, 2009.

43. Hirano K. The roles of proteinase-activated receptors in vascular physiology and pathophysiology. Arterioscler Thromb Vasc Biol. 2007; 27:27-36.

44. Jennings LK. Mechanisms of platelet activation: Need for new strategies to protect against platelet- mediated atherothrombosis. Thromb Haemost. 2009;102:248-257.

45. Morrow DA, Scirica BM, Fox KAA, et al. Evaluation of a novel antiplatelet agent for secondary prevention in patients with a history of atherosclerotic disease: Design and rationale for the thrombin-receptor antagonist in secondary prevention of atherothrombotic ischemic events (TRA 2 ${ }^{\circ}$ P)-TIMI 50 trial. Am Heart J. 2009;158:335-341.e3.

46. Becker RC, Moliterno DJ, Jennings LK, et al. Safety and tolerability of SCH 530348 in patients undergoing non-urgent percutaneous coronary intervention: a randomized, double-blind, placebo controlled phase II study. Lancet. 2009;373:919-928.

47. Goto S, Yamaguchi H, Ikeda Y, et al. Safety and exploratory efficacy of the novel thrombin receptor antagonist SCH 530348 for non-STsegment elevation acute coronary syndrome. $J$ Atheroscler Thromb. 2010;17(2):156-164.

48. The thrombin receptor antagonist for clinical event reduction in acute coronary syndrome (TRA*CER) trial: study design and rationale. The TRA*CER executive and steering committee. Am Heart $J$. 2009;158(3):327-334.e4.

49. Serebruany VL, Kogushi M, Dastros-Pitei D, Flather M, Bhatt DL. The in-vitro effects of E5555, a protease-activated receptor (PAR)-1 antagonist, on platelet biomarkers in healthy volunteers and patients with coronary artery disease. Thromb Haemost. 2009;102:111-119.

50. Dawson DL, Cutler BS, Meissner MH, et al. Cilostazol has beneficial effects in treatment of intermittent claudication: results from a multicenter, randomized, prospective, double-blind trial. Circulation. 1998; 98:678-686

51. Douglas JS Jr, Holmes DR, Kereiakes DJ, et al. Coronary stent restenosis in patients treated with cilostazol. Circulation. 2005;112:2826-2832.

52. Han Y, Li Y, Wang S, et al. Cilostazol in addition to aspirin and clopidogrel improves long-term outcomes after percutaneous coronary intervention in patients with acute coronary syndromes: a randomized, controlled study. Am Heart J. 2009;157:733-739.

53. Brass EP, Anthony R, Cobb FR, et al. The novel phosphodiesterase inhibitor NM-702 improves claudication-limited exercise performance in patients with peripheral arterial disease. J Am Coll Cardiol. 2006; 48:2539-2545.

54. O'Donnell MJ, Hankey GJ. Antiplatelet therapy for secondary prevention of non-cardioembolic ischemic stroke: a critical review. Stroke. 2008;39:1638-1646.

55. Bal Dit Sollier C, Crassard I, Simoneau G, et al. Effect of the thromboxane prostaglandin receptor antagonist terutroban on arterial thrombogenesis after repeated administration in patients treated for the prevention of ischemic stroke. Cerebrovasc Dis. 2009;28:505-513. 
56. Hennerici MG; PERFORM Study Investigators. Rationale and design of the Prevention of Cerebrovascular and Cardiovascular Events of Ischemic Origin with Terutroban in Patients with a History of Ischemic Stroke or Transient Ischemic Attack (PERFORM) Study. Cerebrovasc Dis. 2009;27:28-32.

57. Bousser MG, Amarenco P, Chamorro A, et al; for PERFORM Study Investigators. Rationale and design of a randomized, double-blind, parallel-group study of terutroban $30 \mathrm{mg}$ /day versus aspirin $100 \mathrm{mg} /$ day in stroke patients: the prevention of cerebrovascular and cardiovascular events of ischemic origin with terutroban in patients with a history of ischemic stroke or transient ischemic attack (PERFORM) study. Cerebrovasc Dis. 2009;27:509-518.

58. Norgren L, Jawien A, Mátyás L, et al; for European MCI-9042 Study Group. Sarpogrelate, a 5-hT2A receptor antagonist in intermittent claudication. A phase II European study. Vasc Med. 2006;11:75-83

59. Shinohara Y, Nishimaru K, Sawada T, et al; for S-ACCESS Study Group. Sarpogrelate-aspirin comparative clinical study for efficacy and safety in secondary prevention of cerebral infarction (S-ACCESS): a randomized, double-blind, aspirin-controlled trial. Stroke. 2008;39:1827-1833.

60. Gilbert JC, DeFeo-Fraulini T, Hutabarat RM, et al. First-in-human evaluation of anti von Willebrand factor therapeutic aptamer ARC1779 in healthy volunteers. Circulation. 2007;116:2678-2686.

61. Spiel AO, Mayr FB, Ladani N, et al. The aptamer ARC1779 is a potent and specific inhibitor of von Willebrand Factor mediated ex vivo platelet function in acute myocardial infarction. Platelets. 2009;20:334-340.
62. Clinical Trials.gov. Protocol NCT00507338. Study of ARC1779 in Patients With Acute Myocardial Infarction Undergoing PCI (vITAL-1). http://www.clinicaltrials.gov/ct2/show/NCT00507338? term=ARC1779\&rank=6 Accessed Feb 2, 2010.

63. Gresele P, Migliacci R, Procacci A, et al. Prevention by NCX 4016, a nitric oxide-donating aspirin, but not by aspirin, of the acute endothelial dysfunction induced by exercise in patients with intermittent claudication. Thromb Haemost. 2007;97:444-450.

64. Clinical Trials.gov. Protocol NCT01042964. Safety, pharmacokinetic and -dynamic study of PR-15, an inhibitor of platelet adhesion (PR15/01). http://www.clinicaltrials.gov/ct2/show/NCT01042964?term=PR-15\&rank=1 Accessed Feb 8, 2010.

65. Cataldo G, Heiman F, Lavezzari M, et al. Indobufen compared with aspirin and dipyridamole on graft patency after coronary artery bypass surgery: results of a combined analysis. Coron Artery Dis. 1998; 9:217-222.

66. Morocutti C, Amabile G, Fattapposta F, et al. Indobufen versus warfarin in the secondary prevention of major vascular events in nonrheumatic atrial fibrillation. SIFA (Studio Italiano Fibrillazione Atriale) investigators. Stroke. 1997;28:1015-1021.
Journal of Blood Medicine

\section{Publish your work in this journal}

The Journal of Blood Medicine is an international, peer-reviewed, open access, online journal publishing laboratory, experimental and clinical aspects of all topics pertaining to blood based medicine including but not limited to: Transfusion Medicine; Blood collection, Donor issues, Transmittable diseases, and Blood banking logistics; Immunohematology; Artificial and alternative

\section{Dovepress}

blood based therapeutics; Hematology; Biotechnology/nanotechnology of blood related medicine; Legal aspects of blood medicine; Historical perspectives. The manuscript management system is completely online and includes a very quick and fair peer-review system. Visit http://www.dovepress.com/ testimonials.php to read real quotes from published authors. 